\title{
Terlipressin and Octreotide in Esophageal Varices: A Comparative Study
}

\author{
Rasmirekha Behera ${ }^{1}$,Sushant Sethi ${ }^{2}$ \\ ${ }^{I}$ Dept Of Pharmacology I.M.S \& SUM Hospital Bhubaneswar,India \\ ${ }^{2}$ Dept Of Gastroenterology Apollo Hospital Bhubaneswar,India
}

\begin{abstract}
Aim: To Compare the role of Terlipressin And Octreotide in Esophageal Varices

Methods: 30 Cirrhotic Patients with esophageal variceal bleed were taken into consideration.15 Patients (Group A) were given Terlipressin in the does of $2 \mathrm{~g}$ bolus i.v every 4 hours first 2 days.The dose is halved after bleeding controlled \& maintained up to 5 days and other 15 Patients were given octreotide in the dose of initial IV bolus $50 \mu \mathrm{g}$ followed by a continuous infusion of $50 \mu \mathrm{g}$ per hour. The infusion maintained for 5 days.Two groups were compared for efficacy and safety.

Result: Total 30 patients were included in the study.Baseline characteristics of two groups were comparable for age, $\mathrm{Hb}$ at presentation,Pulse rate,Systolic and Diastolic B.P.Statistical Analysis was done using unpaired T test.

Conclusion: The efficacy of Terlipressin was not inferior to Octreotide as an adjuvant therapy for the control of esophageal variceal bleed.
\end{abstract}

Keywords: Variceal Bleed,Cirrhosis,Portal Hypertension,Terlipressin,Octreotide

\section{Introduction}

Variceal bleeding is a major complication of portal hypertension and represents leading cause of death in patients with cirrhosis. $(1,2)$ Early mortality after an episode of acute variceal bleeding remains high (15\%$24 \%)(1,2,3,4,5)$ Ruptured esophageal varices cause approximately $70 \%$ of all upper gastrointenstinal (GI) hemorrhages in cirrhosis.(6)Therefore, a variceal origin should be suspected in any cirrhotic patient presenting with a GI bleeding until a diagnostic endoscopy is performed.

Esophageal variceal bleeding is a medical emergency that carries high mortality despite appropriate management.Endoscopic intervention along with pharmacological treatment achieves control of bleeding in nearly $70-80 \%$ of episodes of variceal bleeding.(7)Endoscopic variceal band ligation (EVL) has been the recommended preferred procedure for the control of acute variceal bleeding,although endoscopic injection sclerotherapy(EIS) can be used in this setting if EVL proves technically difficult.(8) Adjuvant pharmacological treatment is the standard of care along with EVL for the control of esophageal variceal bleeding.

Terlipressin and Octreotide are two common agents used as an adjuvant agent in the management of variceal bleeding. $(9,10)$ Vasopressin is the most potent splanchnic vasoconstrictor.It reduces blood flow to all splanchnic organs, thereby leading to a decrease in portal venous inflow and to a decrease in portal pressure.The clinical usefulness of vasopressin is limited by its multiple side effects, which are related to its potent vasoconstrictive properties,including cardiac and peripheral ischemia,arrhythmias, hypertension and bowel ischemia.(11)

Terlipressin,a synthetic analogue of vasopressin that has a longer biological activity and significantly fewer side effects,ie effective in controlling acute variceal hemorrhage and has been associated with a decrease mortality.(12)Terlipressin is given as a $2 \mathrm{~g}$ bolus dose every 4 hours during the first $2 \mathrm{~d}$.The dose is halved after bleeding is controlled and can be maintained for up to 5 days.Administration of terlipressin at low doses in continuous perfusion has been tested in cirrhotic patients with septic shock with promising results. $(13,14)$ Natural somatostatin also causes splanchnic vasoconstriction at therapeutical doses and has proven to reduce portal pressure and hepatic venous pressure gradient (HVPG) During active bleeding. $(15,16,17,18)$ Somatostatin blocks the postprandial increase in portal blood flow and portal pressure.Somatostatin usually given at a continuous perfusion dose of $250 \mathrm{mcg} / \mathrm{h}$ after an initial $250 \mathrm{mcg}$ bolus (which can be repeated up to 3 times during the first hour).The infusion should be maintained for 5 d.(19) or until a $24 \mathrm{~h}$ period free of rebleeding has been achieved.

Octreotide is a synthetic analogue of natural somatostatin with similar mechanism of action and longer half life.However,this does not result in longer hemodynamic effects, $(20,21)$ probably due to the development of tachyphylaxis or rapid desensitization.(22)Octreotide used as an initial I.V bolus $50 \mu \mathrm{g}$ followed by a continuous infusion of $50 \mu \mathrm{g}$ per hour. Octreotide is indeed effective in preventing early rebleeding with no apparent effect on mortality.(23)It has been speculated that this beneficial effect of octreotide may be related to its capacity of blunting postprandial increase in portal pressure.(24) 


\section{Study Population}

\section{Material And Methods}

Patients with cirrhosis who presented to the emergency room with upper gastrointenstinal bleed (GI) bleed were included in the study.Total 30 patients were included in the study.

\section{Exclusion Criteria}

Patients with nonvariceal bleed on endoscopy.Patients with gastric variceal /portal hypertensive gastropathy related bleed on endoscopy. Patient underwent sclerotherapy for esophageal varceal bleed Place of Study Apollo Hospital Bhubaneswar, India

Methods: Out of 30 patients 15 patients were included in Group A and 15 patients were included in Group B. Group A received terlipressin $2 \mathrm{~g}$ bolus dose every hours during first 2 days. The dose is halved after bleeding is controlled and maintained up to 5 days. Group B received octreotide initial I.V bolus $50 \mu \mathrm{g}$ followed by a continuous infusion of $50 \mu \mathrm{g}$ per hour. The infusion is maintained for 5 days. All the patients were observed for 5 days.

\section{Statistical Analysis}

Statistical Analysis was done by applying unpaired t-test.

\section{Result}

\begin{tabular}{|l|l|l|l|}
\hline Parameters & Terlipressin & Octreotide & P value \\
\hline Age(yrs) & $50.2 \pm 2.6$ & $48.8 \pm 2.5$ & $<0.1$ \\
\hline Hb at presentation & $8.6 \pm 0.9$ & $8.3 \pm 1.5$ & $<0.5$ \\
\hline Pulse in ER(beats/min) & $90.0 \pm 4.5$ & $95.8 \pm 4.03$ & $<0.001$ \\
\hline $\begin{array}{l}\text { Systolic BP in ER } \\
\text { (mmHg) }\end{array}$ & $108.9 \pm 6.4$ & $103.3 \pm 6.3$ & $<0.05$ \\
\hline $\begin{array}{l}\text { Diastolic BP in ER } \\
\text { (mmHg) }\end{array}$ & $70.2 \pm 8.5$ & $73.7 \pm 8.1$ & $<0.1$ \\
\hline
\end{tabular}

BP: Blood Pressure,ER:Emergency Room,Hb:Hemoglobin,yrs:Years

(Table-1) Comparision of Terlipressin and Octreotide groups of patients in whom control of Variceal Bleed was achieved
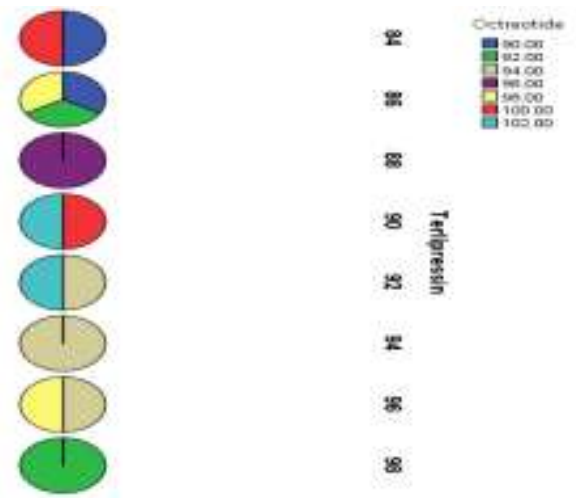

(Graph-1)Comparision of Pulse Rate Between Terlipressin and Octreotide

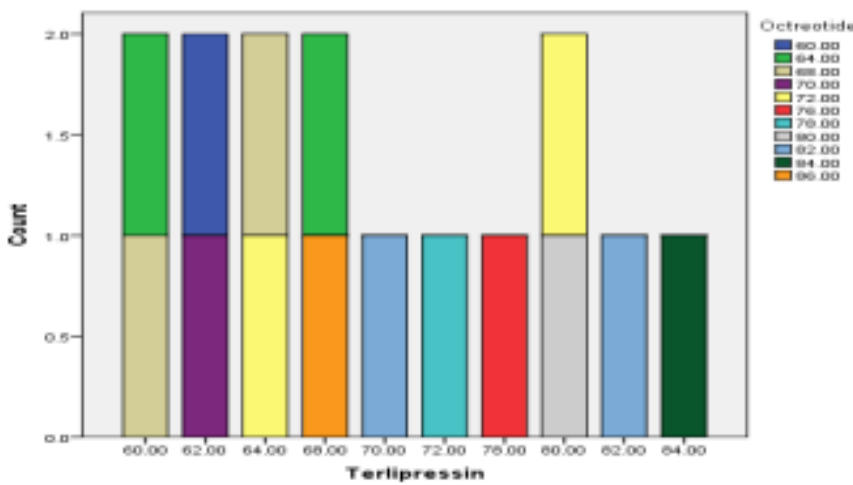

(Graph-2) Effect of Terlipressin and Octreotide on Diastolic B.P 
Graph-1 shows comparision of pulse rate after administration of Terlipressin and Octreotide.Graph -2 shows the effect of Terlipressin and Octreotide on Diastolic B.P. Above two graph indicates there is not much difference in Diastolic B.P and Pulse rate in between patients receiving Terlipressin and Octreotide.

\section{Discussion}

Esophageal variceal band lagation (EVL) had replaced injection sclerotherapy (EIS) for Esophageal Variceal Bleed (EVB) as EVL was superior to EIS.(25) Both transjugular intrahepatic portosystemic shunts (TIPS) and surgical derivative procedures are extremely effective controlling variceal bleeding in patients who fail to respond to initial pharmacological and endoscopic therapies.However the incidence of encephalopathy and mortality remains very high in shunt therapies.(26,27) Terlipressin a synthetic analogue of vasopressin with longer activity and fewer side effects.It reduces portal pressure and its effects are still significant 4 hours after administration. $(28,29,30)$ Somatostatin and analogues such as Octreotide also cause splanchnic vasoconstriction at pharmacological doses.

\section{Conclusion}

There is no significant change in different parameters between terlipressin and octreotide treated patients.Hence it is suggested from our study that terlipressin was noninferior to octreotide in its efficacy to control variceal bleed when used as adjuvant agent in combination with endoscopic band ligation in patients with esophageal variceal bleed.

\section{References}

[1]. Graham DY,Smith JL.The course of patients after variceal hemorrhage.Gastroenterology 1981;80:800-809.

[2]. Gines P,Quintero E,Arroyo V,Teres J,Bruguera M,Rimola A.Compensated Cirrhosis:natural history and prognostic factors.Hepatology 1987; 7:122-128.

[3]. El-Serag HB,Everhart JE.Improved survival after variceal hemorrhage over an 11-year period in the Department of Veterans affairs.Am J Gastroenterol 2000;95:3566-3573.

[4]. Mc Cormick PA,O'Keefe C.Improving prognosis following a first variceal haemorrhage over four decades.Gut 2001;49:682-685

[5]. Augustin S,Muntaner L,Altamirano JT, Gonzalez A,Saperas E,Dot J,Abu-Suboh M,Armengol JR,Malagelada JR,Esteban R,Guardia J,Genesca J,Predicting early mortality after acute variceal hemorrhage based on classification and regression tree analysis.Clin Gastroenterol Hepatol 2009; 7:1347-1354

[6]. D'Amico G,De Franchis R,Upper digestive bleeding in cirrhosis.Post-therapeutic outcome and prognostic indicators.Hepatology 2003;38:599-612.

[7]. D’Amico G,Pietrosi G,Tarantino I et al, Emergency sclerotherapy versus vasoactive drugs for variceal bleeding in cirrhosis:a Cochrane meta-analysis.Gastroenterology 2003;124:1277-91.

[8]. de Franchis R,Evolving consensus in portal hypertension report of the Baveno IV consensus workshop

[9]. on methodology of diagnosis and therapy in portal hypertension.J Hepatol 2005;43:167-76.

[10]. Escorsell A,Arbol LRD,Planas R et al.Multicenter randomized controlled trial of terlipressin versus sclerotherapy in the treatment of acute variceal bleeding:the TEST study.Hepatology 2000;32:471-6.

[11]. Bildozola M,Kravetz D,Argonz $J$ et al.Efficacy of octreotide and sclerotherapy in the treatment of acute variceal bleeding in cirrhotic patients.A prospective,multicentric and randomized clinical trial.Scand J Gastroenterol 2000;35:419-25.

[12]. Bolognesi M,Balducci G,Garcia-Tsao G,Gatta A,Gines P,Merli M,et al.Complications in the medical treatment of portal hypertension.Portal Hypertension III.Proceedings of the Third Baveno International Consensus Workshop on Definitions,Methodology and therapeutic Strategies.Oxford,UK:Blackwell Science,2001:180-203.

[13]. D'Amico G,Pagliaro L,Bosch J,Pharmacological treatment of portal hypertension:an evidence based approach.Semin Liver Dis 1999;19:475-505.

[14]. Morelli A,Ertmer C,Lange M,Westphal M.Continuous terlipressin infusion in patients with septic shock:less may be best,and the earlier the better?Intensive Care Med 2007;33:1669-1670.

[15]. Umgelter A,Reindl W,Schmid RM,Huber W.Continuous terlipressin infusion in patients with persistent septic shock and cirrhosis of the liver.Intensive Care Med 2008;34:390-391.

[16]. Villanueva C,Ortiz J,Minana J,Soriano G,Sabat M,Boadas J,Balanzo J.Somatostatin treatment and risk stratification by continuous portal pressure monitoring during acute variceal bleeding.Gastroenterology 2001;121:110-117.

[17]. Cirera I,Feu F,Luca A,Garcia-Pagan JC,Fernandez M,Escorsell A,Bosch J,Rodes J.Effects of bolus injections and continuous infusion of somatostatin and placebo in patients with cirrhosis :a double-blind hemodynamic investigation.Hepatology 1995;22:106111.

[18]. Nevens F,Sprengers D,Fevery J.The effect of different doses of a bolus injection of somatostatin combined with a slow infusion on transmural oesophageal variceal pressure in patients with cirrhosis.J Hepatol 1994;20:27-31.

[19]. Burroughs AK,McCormick PA,Hughes MD,Sprengers D,D'Heygere F,Mclntyre N.Randomized,double-blind,placebo-controlled trial of somatostatin for variceal bleeding.Emergency control and prevention of variceal rebleeding.Gastroenterology 1990;99:13881395 .

[20]. Escorsell A,Bordas JM,Del Arbol LR,Jaramillo JL,Planas R,Banares R.Randomized controlled trial of sclerotherapy versus somatostatin infusion in the prevention of early rebleeding following acute variceal hemorrhage in patients with cirrhosis.Varceal Bleeding Study Group.J Hepatol 1998;29:779-788.

[21]. Jenkins SA,Nott DM,Baxter JN.Pharmacokinetics of octreotide in patients with cirrhosis and portal hypertension;relationship between the plasma levels of the analogue and the magnitude and duration of the reduction in corrected wedged hepatic venous pressure.HPB Surg 1998;11:13-21.

[22]. Moller S,Brinch K,Henriksen JH,Becker U.Effect of octreotide on systemic,central,and splanchnic haemodynamics in cirrhosis.J Hepatol 1997;26:1026-1033.

[23]. Escorsell A,Bandi JC,Andreu V,Moitinho E,Garcia-Pa-gan JC,Bosch J,Rodes J.Desensitization to the effects of intravenous octreotide in cirrhotic patients with portal hypertension.Gastroenterology 2001;120:161-169. 
[24]. Corley DA,Cello JP,Adkisson W,Ko WF,Kerlikowske K.Octreotide for acute esophageal variceal bleeding:a metaanalysis.Gastroenterology 2001;120:946-954.

[25]. Abraldes JG,Bosch J.Somatostatin and analogues in portal hypertension.Hepatology 2002;1305-1312.

[26]. Gross M,Scheimann U,Muhlhofer A et al.Meta-analysis:efficacy of therapeutic regimens in ongoing variceal bleeding.Endoscopy 2001;33:737-46.

[27]. D'Amico G,Pagliaro L,Bosch J.The treatment of portal hypertension:a meta-analytic review.Hepatology 1995;22:332-354.

[28]. Bosch J.Salvage transjugular intrahepatic portosystemic shunt:is it really a life-saving?J Hepatol 2001;35:658-660.

[29]. Nevens F.Non-invasive variceal pressure measurements:validation and clinical implications.Verh K Acad Geneeskd Belg 1996;58:413-437.

[30]. Moreau R,Soubrane O,Hadengue A,Sogni P,Gaudin C,Kleber G,Lebrec D.[Hemodynamic effects of the administration of terlipressin alone or combined with nitroglycerin in patients with cirrhosis].

[31]. Gastroenterol Clin Biol 1992;16:680-686.

[32]. Escorsell A,Bandi JC,Moitinho E,Feu F,Garcia-Pagan JC,Bosch J.Time profile of the haemodynamic effects of terlipressin in portal hypertension.J Hepatol 1997;26:621-627. 